DOI: $10.5277 /$ epe 160313

\author{
MICHAL ZIELINA ${ }^{1}$
}

\title{
MONITORING PARTICLE SIZE DISTRIBUTION FOR WATER TREATMENT PROCESSES
}

\begin{abstract}
Efficiencies of unit processes such as flocculation, sedimentation and filtration were analyzed based on particle size distribution in one of the several water treatment plants supplying Cracow (Poland). The predicted efficiencies determined based on concentration of volumetric suspension, nephelometric turbidity and absorbance were compared with each other. Interpretation of the results was proposed based on the Mie scattering theory. The results of theoretical analysis suggested much stronger influence of finer particles on absorbance and nephelometric turbidity than that of larger particles. The experimental results confirmed this suggestion. Hence, the more efficient removal of larger particles during the process resulted in a higher efficiency of the process based on the concentration of volumetric suspension than those predicted based on the nephelometric turbidity or absorbance. For a rapid filtration process, which is strongly dynamic, relation was analyzed for various filter run times.
\end{abstract}

\section{INTRODUCTION}

Numerous unit processes have been employed in water treatment technology, coagulation, flocculation, sedimentation, filtration and disinfection being the most commonly used ones. The choice of optimal working parameters for each of them is one of the design principles. Unfortunately, all these processes are very dynamic and strongly dependent on rapidly changing conditions and raw water quality. Hence, optimal working parameters guaranteeing relatively low operational costs and effective reduction of contaminants also change dynamically over time. Sophisticated mathematical descriptions reveal a strong dependence of these processes on quality parameters of raw water such as temperature, $\mathrm{pH}$, conductance and alkalinity, as well as on parameters characterizing suspended particles, i.e.: size, surface potential (indirectly measured by electro -kinetic zeta potential), shape and roughness of particle surfaces, and porosity and density of particles or flocs. Among these, suspended particle size distribution seems to be

${ }^{1}$ Water Supply and Environmental Protection Institute, Cracow University of Technology, ul. Warszawska 24, 31-155 Cracow, Poland, e-mail:email: mziel@ vistula.wis.pk.edu.pl 
quite important [1]. A few methods for measurement of particle size distribution (PSD) have been developed to a significant extent over the past decade. The laser light scattering method seems to be quite promising for water technology. It is a relatively fast technique which can be used online. Particle-sizing instruments usually use the Mie theory as the one which most precisely describes light-scattering phenomena. Unfortunately, the Mie theory precisely describes only light scattering through transparent, even, spherical particles. Suspended particles in natural water are often colored, uneven, non -spherical and characterized by various refractive indices. Error created by natural conditions can be reduced by using a complex refractive index including both real and imaginary parts [2]. The imaginary part of a refractive index describes absorption loss through non-transparent particles. Light scattering through suspended particles larger than several microns are much easier to describe because the results are almost independent of particle refractive indices [3]. In such cases it is possible to use even the old, simple Fraunhofer theory successfully. Theoretical results for this kind of particles are more certain than for smaller particles. The fundamentals of light scattering theory suggest that the intensity of light scattered at a low angle increases upon increasing particle size [4].

The Mie theory is the only one that precisely describes light scattering for a wide range of particle sizes [5]. The basic rule of the theory suggests that shorter light waves are scattered more intensively through finer particles than larger ones. Inversely, longer light waves are scattered more intensively through larger particles. The higher refractive index of particles compared to the refractive index of water means a higher scattering angle. Generally, organic particles are characterized by lower refractive indices than minerals [6]. Some observations [7] suggest that different particle shapes, rather than spherical effects, decrease the intensity of transmitted light and scatter it at a smaller angle compared to the intensity of light scattered at a greater angle.

Naturally colored particles absorb light and only its part is re-emitted by the particles. Hence, transmitted and also scattered light intensities are reduced. The lower the scattered light intensity at a $90^{\circ}$ angle, the lower the nephelometric turbidity is. Lower transmitted light intensity results in higher absorbance turbidity.

Distribution of particle size is a useful tool for decision-making in water treatment plants. Operators receive more information about processes that help them remove particles which are the same size as the most dangerous pathogens. Particle size distribution characterises the quality of treated water more precisely than its turbidity. In consequence, the probability of epidemiological dangerous tap water can be significantly reduced. The research results [8] reveal a quite high correlation between Giardia and Cryptosporidium oocysts and particles smaller than $5 \mu \mathrm{m}$ and also [9] between viable bacteria and particles smaller than eight $8 \mu \mathrm{m}$. Monitoring particle size distributions can facilitate matching selecting optimal dosed of coagulant [10]. 


\section{THEORETICAL BACKGROUND}

Turbidimeters are commonly used in water treatment plants for monitoring the volume of suspended solids in water and predicting the removal efficiency of the unit processes. Turbidity is one of the few water quality indices available to be measured online over a wide range of suspension concentrations with relatively high accuracy and repeatability. However, turbidity strongly depends not only on concentration of suspension but also on the sizes of particles scattered in water. The function describing the dependence of turbidity on particle size is very complex, making interpretation of the turbidity parameter difficult.

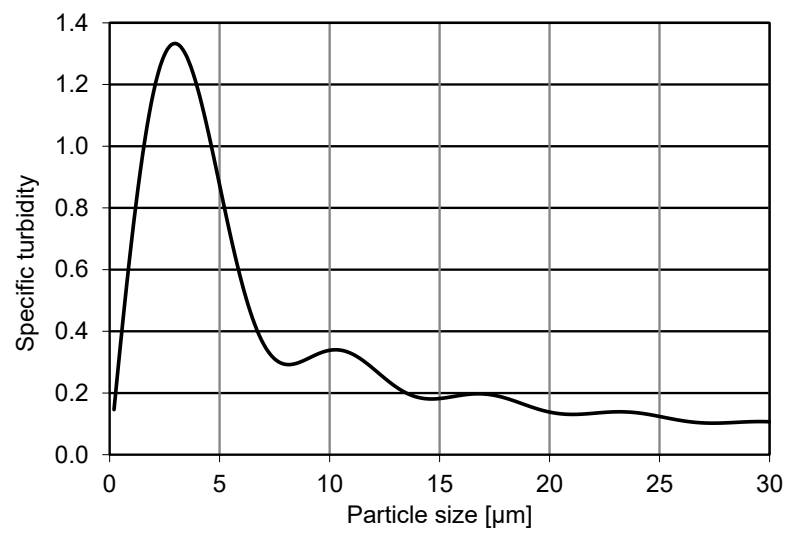

Fig. 1. Specific turbidity (absorbance per unit concentration) defined as turbidity (absorbance) divided by particle volume versus particle diameter

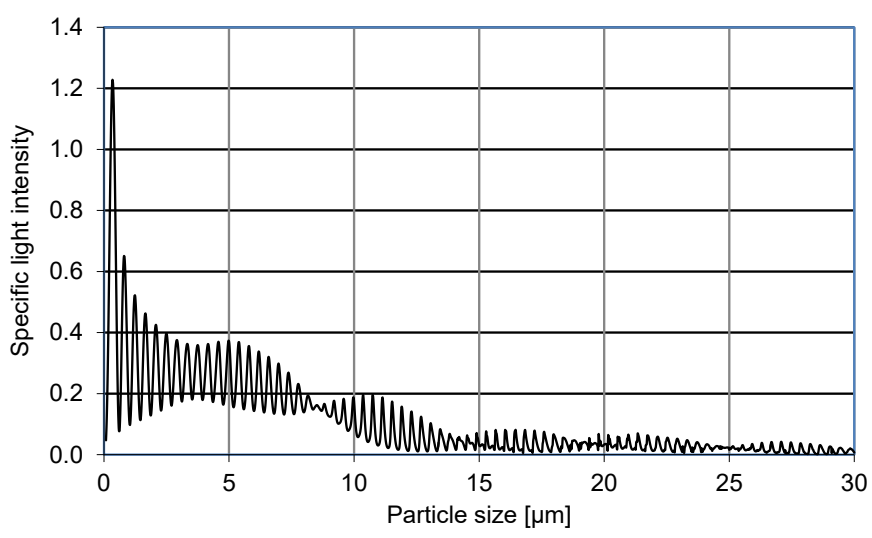

Fig. 2. Specific light intensity scattered at an angle of $90^{\circ}$ (nephelometric measurement) defined as light intensity at $90^{\circ}$ divided by the particle volume versus particle diameter 
Figures 1 and 2 present dependences of light intensity scattered at an angle of $90^{\circ}$ (nephelometric measurement) and specific absorbance on particle size based on numerical calculations according to the Mie theory for transparent, fully spherical particles made from material with the refractive index of 1.51 at $860 \mathrm{~nm}$. Specific the turbidity (absorbance) was defined as turbidity (absorbance) divided by particle volume, i.e. it is the absorbance calculated of $1 \mu \mathrm{m}^{3}$ of suspended solid. Since turbidity is linearly proportional to the concentration of volumetric suspension, specific turbidity is independent on suspension concentration and dependence of the turbidity on the particle size (shape of the curve) shown in Fig. 1 will be similar for any suspension concentration. Calculations were carried out based on a freeware computer program MiePlot by Philip Laven (http://www.philiplaven.com/index1.html, Boren, Huffman) and simplified solution for the Mie theory equations [5]. The results reveal the strong dependence of the nephelometric turbidity and absorbance on particle size. Generally, the influence of the unit volume of finer particles on nephelometric turbidity and absorbance is stronger than that of the unit volume of larger particles. This means that turbidity will not change proportionally to the concentration of suspension if the particle size distribution of the suspension will change. Thus, turbidity, as the parameter for estimating the removal efficiency of unit processes, will be strongly influenced by the particle size distributions and will differ from removal efficiency predicted based on suspension concentration depending on particle size distribution.

\section{EXPERIMENTAL}

The experiments were carried out in one of the water treatment plants supplying Cracow (Poland) with water taken from the Dlubnia River. Water is treated with traditional processes such as coagulation, flocculation, sedimentation, filtration and disinfection and occasionally powdered activated carbon. First, the raw water is coagulated continuously with aluminium sulfate. Next, it flows through the horizontal sedimentation tanks and reaches ten rapid filters filled with $1 \mathrm{~m}$ high sand media with the following mass stratification: fraction $0-0.4 \mathrm{~mm}-2.2 \%, 0.4-0.5 \mathrm{~mm}-2.4 \%, 0.5-0.63 \mathrm{~mm}$ $-3.5 \%, 0.63-0.8-5.9 \%, 0.8-1.0-13.6 \%, 1.0-1.25-49.4 \%, 1.3-1.6 \mathrm{~mm}-23 \%$. Effective size of the sand medium $d_{10}$ equaled $0.72 \mathrm{~mm}$ and the uniformity coefficient $d_{60} d d_{10}=1.6$. The conductivity of the treated water was kept close to $0.550 \mathrm{mS} / \mathrm{cm}, \mathrm{pH}=8.2$ and the temperature was $7^{\circ} \mathrm{C}$. Following filtration, the samples with low concentrations were settled and decanted before being measured to obtain a sufficiently high concentration. The suspension concentrations of samples from raw water and after flocculation were optimal for the measurement of particle size distribution and no sample preparation was needed.

Nephelometric turbidity was measured with a Turb 500 IR turbidimeter, manufactured by the WTW company. The volumetric particle size distribution and volumetric 
suspension concentration were predicted using the Mastersizer 2000 particle size analyzer, manufactured by the Malvern Instruments. The Mie theory was applied for calculations particle size distribution curves.

Turbidity and particle size distribution were measured between unit water treatment processes during experiments. However, since even under stable operation conditions, filtrate quality is time dependent, rapid filtration process was closely monitored for few different filter run times.

The shape, porosity, roughness, chemical composition and color of suspended particles changed in the processes [11]. Unfortunately, most of the light scattering theories are valid only for transparent and even spherical particles. It is possible to describe the material of the suspended particles using a complex refractive index that enables application of the Mie theory for natural suspension. Refractive indices for particles suspended in water during experiments were chosen: $1.45+0.003 i$ for raw water, $1.39+0.02 i$ for flocculated water, $1.41+0.01 i$ after sedimentation, and $1.41+0.01 i$ for filtered water. Values of refractive indices were estimated based on literature review [12-17].

Since suspended matter in the river is non-uniform, refractive index for particle size analysis was calculated as an average of refractive indices of all suspended particles in the river water. Suspended matter from the river consists commonly from 10 to $60 \%$ of organic particles and from 40 to $90 \%$ of inorganic particles [12]. However, raw water inflowing to the water treatment plant was treated before by intake screening and grit chamber sedimentation. Both processes remove rather inorganic than organic particles. It is supposed that raw water inflowing to the water treatment plant included more organic than inorganic particles. Based on literature [13-16], the refractive index of microbial cells has been found very close to that of water, taking values in the range of 1.36-1.41. The refractive index for phytoplankton is slightly higher and has been estimated $[17,18]$ to be in the range between 1.39 and 1.45 . The refractive indices of inorganic particles are higher than those of organic ones, common mineral particles have RI in the range 1.5-1.6 [19]. Since suspended matter in the raw water contained more organic particles than inorganic ones, eventually it was assumed that the refractive index of suspended particles in the raw water was 1.45.

Refractive indices of aggregates or flocs are generally very low [20]. The refractive index of wetted flocs is very close to the refractive index of water. Thus, following [21], the refractive index of particles after flocculation was estimated as equal to 1.39. More of the larger flocs are captured in the sedimentation tank, thus the refractive index of particles after sedimentation and filtration is expected to be slightly higher and has been estimated as equal to 1.41. Twardowski [17] reported an imaginary index taking values between 0.001 and 0.100 for bulk particles found in ocean waters. Based on [19], RI was estimated $0.003,0.020$ and 0.010 consequently for river water, after flocculation, after sedimentation and filtration. 


\section{RESULTS AND DISCUSSION}

\subsection{MONITORING OF UNIT PROCESSES IN A WATER TREATMENT PLANT}

The main goal of the experiments was to find the relationship between turbidity and concentration of suspension in the unit processes of the water treatment plant and verify this dependence on particle size distribution. The results of measurement of turbidities and concentrations of volumetric suspension of the samples collected between unit processes in the Dłubnia water treatment plant are presented in Table 1.

Table 1

Nephelometric turbidity, absorbance and concentration of suspension after each of the water treatment unit processes

\begin{tabular}{|l|c|c|c|c|}
\hline \multicolumn{1}{|c|}{ Parameter } & $\begin{array}{c}\text { Raw } \\
\text { water }\end{array}$ & $\begin{array}{c}\text { After } \\
\text { flocculation }\end{array}$ & $\begin{array}{c}\text { After } \\
\text { sedimentation }\end{array}$ & $\begin{array}{c}\text { After } \\
\text { rapid filtration }\end{array}$ \\
\hline Turbidity, NTU & 42.4 & 47.6 & 1.46 & 0.35 \\
\hline Absorbance & 0.0703 & 0.1002 & 0.0040 & 0.0017 \\
\hline $\begin{array}{l}\text { Concentration of volumetric suspension } \\
\text { measured by a laser instrument, ppm] }\end{array}$ & 262 & 394 & 9 & 1.8 \\
\hline
\end{tabular}

Volumetric particle size distributions were also measured with a particle size analyzer for samples taken between processes. Figures 3 and 4 present particle size distributions for each of the collected samples as a cumulative percentage frequency and also as a probability density function. As expected, due to the high hydration of flocs after flocculation causing an increase in total suspended particle volume, no reduction, and even an increase was observed in both parameters.

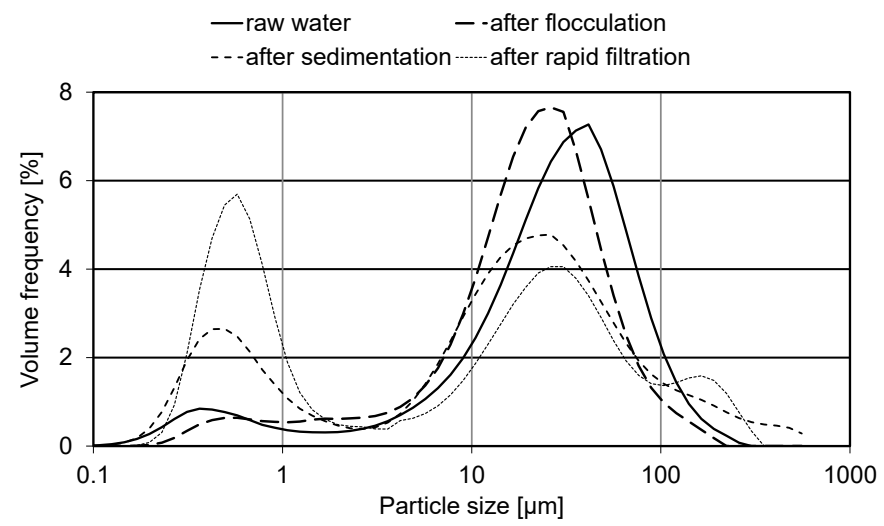

Fig. 3. Frequency distributions for samples between unit processes of the Dłubnia River water treatment plant 


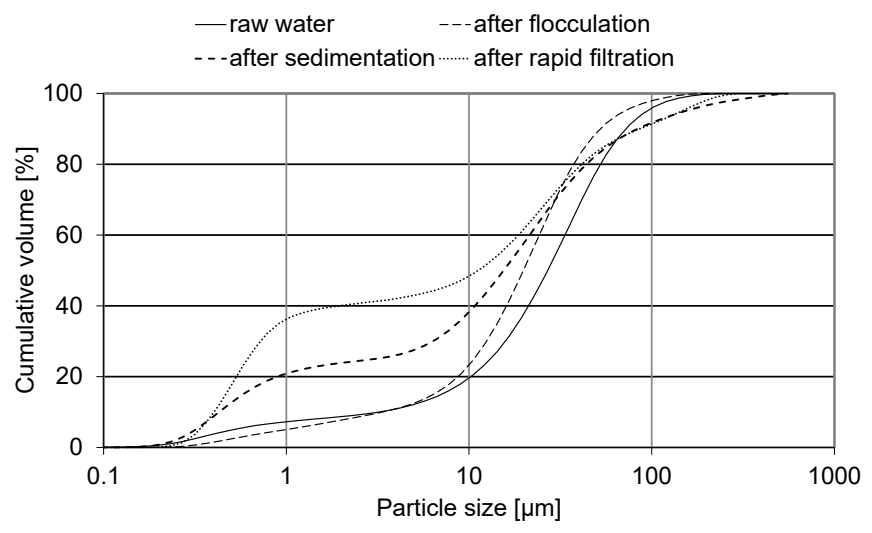

Fig. 4. Cumulative undersize distributions for samples between unit processes of the Dłubnia River water treatment plant

However, the increase in turbidity was not as great as that in suspension concentration. This was due to the decrease (shown in Figs. 3 and 4) in the relative volume of particles finer than $1 \mu \mathrm{m}$ in the total suspended solid volume after flocculation, whereas the relative volume of larger particles increased. As shown in Fig. 2, the influence of particles larger than $1 \mu \mathrm{m}$ was much weaker on turbidity than that of finer particles. Consequently, the increase in turbidity was not as significant as in the total suspended particle volume.

The most important reduction in turbidity and suspension concentration was observed after sedimentation. Flocculated particles were effectively reduced in the sedimentation tank. However, the decrease in suspension concentration (almost 45 times) was much stronger than the decrease in turbidity (about 30 times). This could be explained by the increase in the relative amount of fine particles (smaller than $1 \mu \mathrm{m}$ ) in the total volume of suspended solids, whereas the relative amount of larger particles after sedimentation decreased (Figs. 3 and 4). As a consequence of the stronger influence of finer particles on the nephelometric turbidity than that of larger particles (Fig. 1), the reduction in nephelometric turbidity was weaker than in suspension concentration. Some particles larger than $100 \mu \mathrm{m}$ were removed less efficiently than the rest of the particles. Probably some of the larger, strongly hydrated flocs characterizing by low density settled too slowly to be trapped in the sedimentation tank. Such large particles should not flow into the filters, because they can block pores in the upper layers of the sand media. However, there could be a small number of such large particles, since the increase in particle diameter causes particle volume to increase cubically. Filtration reduced nephelometric turbidity from 1.46 NTU in the inflow to the filter to 0.35 NTU in the outflow. The turbidity of filtrate was significantly below Polish standards (1 NTU). Simultaneously, the concentration of suspension was also reduced by filtration by a factor of around 6. As expected, larger particles were removed much more efficiently than 
the smaller ones. Particles with a size of $1 \mu \mathrm{m}$ were reduced the most poorly by filtration which was in agreement with theoretical predictions [12]. Surprisingly, a quite significant number of particles larger than $100 \mu \mathrm{m}$ were not removed, probably due to the detachment of some deposited aggregates, and reached the filtrate.

The results presented in Table 1 show a higher removal efficiencies for sedimentation and filtration processes determined based on the concentration of volumetric suspension than those predicted based on the nephelometric turbidity. Larger particles were removed more efficiently during filtration and sedimentation. Particle size distributions prior to these processes were characterizing by a proportionally higher volume of larger particles compared to smaller particles than those following these processes. Consequently, removal efficiency calculated based on the nephelometric turbidity was lower than that calculated based on the concentration of volumetric suspension. Light scatters through the larger particles proportionally more intensively at a lesser angle than at a greater one and this proportion increases along with particle size. Thus the reduction of the nephelometric turbidity measured at $90^{\circ}$ was smaller than that of the volumetric suspension concentration.

\subsection{MONITORING OF A RAPID SAND FILTER}

Filtration is a very dynamic process and should be continuously monitored [13]. The filtration process at the Dlubnia River water treatment plant has been monitored with a particle size analyzer and turbidimeters. Samples from the filter inflow and outflow were taken after some periods of time $(1.5 \mathrm{~h}, 8 \mathrm{~h}, 15 \mathrm{~h}, 19 \mathrm{~h}$ and $25 \mathrm{~h})$ after filter backwash. Based on the measurement of samples, the cumulative particle undersize distribution curves of the inflow and outflow to/from the rapid filter were plotted in Fig. 5.

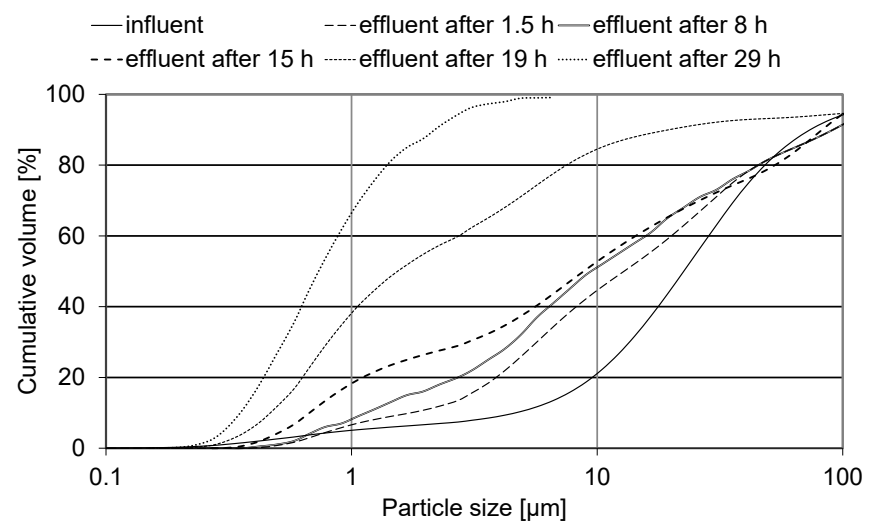

Fig. 5. The cumulative undersize distributions for the samples taken from the influent and effluent to/from filter at the Dłubnia River water treatment plant after different filtration run times 
It can be clearly seen that the percentage of particles smaller than $5 \mu \mathrm{m}$ was higher in the outflow than in the inflow and gradually increased over time. Since particles finer than $5 \mu \mathrm{m}$ were less efficiently reduced in the filter than larger particles, the concentration of total volumetric suspension must have been reduced more strongly than the nephelometric turbidity and absorbance, which is in accordance with the results of the experiment shown in Fig. 6. As the volumetric percentage of particles finer than $5 \mu \mathrm{m}$ in the total suspended solid in the outflow also increases over time (Fig. 5), the concentration of volumetric suspension was reduced even more strongly than turbidity at the end of the run than initially, which is verified in Fig. 6.

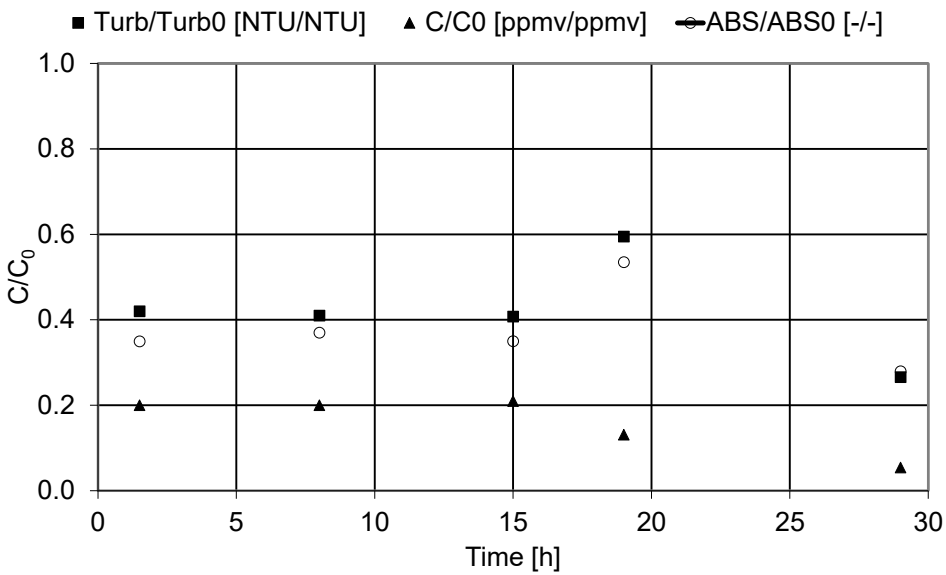

Fig. 6. Normalized concentration of the filter effluent volumetric suspension, normalized effluent nephelometric turbidity and normalized effluent absorbance during filtration at the Dłubnia River water treatment plant

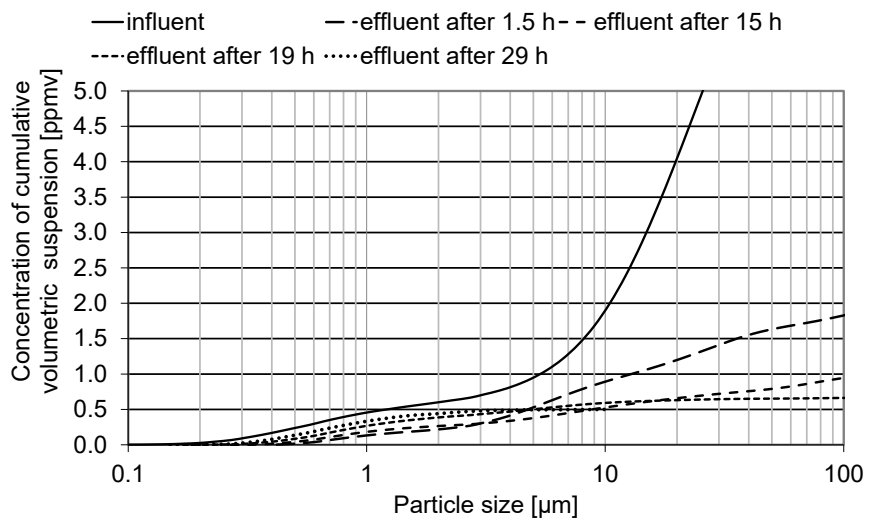

Fig. 7. Concentration of cumulative volumetric suspension in function of particle size 
It was clearly seen in Fig. 5 that larger particles were reduced more significantly than finer particles and over the time removal of larger particles increased more intensively than that of smaller particles. Figure 7 presents absolute values of the concentration of cumulative suspension, not relative values as in Fig. 5. The slopes of the effluent curves above $3 \mu \mathrm{m}$ were visibly smaller than that of the influent curve and decreased over time, which means that removal of particles greater than $3 \mu \mathrm{m}$ was very high and increased significantly over time. However, the slopes of the effluent curves below $3 \mu \mathrm{m}$ were not much smaller than those of influent curves, which means that removal of particles in this range was much weaker than particles larger than $3 \mu \mathrm{m}$ and did not change significantly over time. The slopes of the effluent curves below $1 \mu \mathrm{m}$ after $15 \mathrm{~h}$ even slightly increased which means decrease of removal of particles smaller than $1 \mu \mathrm{m}$ or coagulation of colloidal particles causing an increase of the amount of particles close to $1 \mu \mathrm{m}$ in size in the outflow.

\section{CONCLUSIONS}

Experiments confirmed the results of numerical analysis carried out based on the Mie theory suggesting dependence of nephelometric turbidity and absorbance on the particle size. Generally, finer particles much stronger influence turbidity than larger particles. Since particles of different sizes are removed with varying efficiency by water treatment unit processes, the efficiencies of these processes predicted based on turbidity differ from those predicted based on the suspension concentration using a particle size distribution analyzer. The more efficient removal of larger particles compared to finer ones results in a higher efficiency of the process predicted based on the concentration of volumetric suspension than that predicted based on the turbidity or absorbance. The analysis of the particle size distribution is intended to complete the data collected from a turbidimeter for optimization of water treatment unit processes. Online particle size data enables operators to better control the quality of produced water, choosing the most optimal working parameters and protecting against epidemiological dangers. Particle size distribution analyzers appear to be quite useful instruments, suitable for making decisions on the operation of unit water treatment processes.

\section{ACKNOWLEDGEMENT}

The research was sponsored by the Polish Ministry of Education and Science, grant No. 1235/T09/2005/28 from 2005 to 2007.

\section{REFERENCES}

[1] GAJEWSKA M., Fluctuation of nitrogen fraction during wastewater treatment in a multistage treatment wetland, Environ. Prot. Eng., 2011, 37 (3), 119. 
[2] Craig F.B., Huffman D.R., Absorption and Scattering of Light by Small Particles, Wiley, Weinheim 1998.

[3] JONES R.M., Particle size analysis by laser diffraction: ISO 13320, standard operating procedures, and Mie theory, Amer. Lab., 2003, 1, 44.

[4] SADAR M., Turbidity Science, Technical Information Series, Booklet. 11, Hach Company, Loveland, Col., USA, 1998.

[5] Elimelech M., Jia X., Gregory J., Williams R.A., Particle deposition and aggregation. Measurement, modelling and simulation, Butterworth-Heinemann, Woburn 1995.

[6] Gregory J., Turbidity and beyond, Filtr. Sep., 1998, 35 (1), 63.

[7] McMillan G.K., Considine D.M., Process/Industrial Instruments and Controls Handbook, McGraw-Hill, 5th Ed., USA, 1999.

[8] LeCheVAlLier M.W., Northon W.D., Examining relationship between particle counts and Giarda, Cryptosporidium and turbidity, J. Am. Water Works Assoc., 1992, 84 (12), 54.

[9] KOBler D., BOLler M., Particle removal in different filtration systems for tertiary wastewater treatment. A comparison, Water Sci. Technol., 1997, 36 (4), 259.

[10] GumiŃsKa J., KŁos M., Analysis of post-coagulation properties of flocs in terms of coagulant choice, Environ. Prot. Eng., 2012, 38 (1), 103.

[11] Zielina M., Particle shapes in the drinking water filtration process, Clean: Soil, Air, Water, 2011, 39 (11), 941.

[12] Galloway J.M., Determination of Organic and Inorganic Percentages and Mass of Suspended Material at Four Sites in the Illinois River in Northwestern Arkansas and Northeastern Oklahoma, 2005-07, Scientific Investigations Report 2008-5136, U.S. Geological Survey, Reston 2008.

[13] Valkenburg J.A.C., Woldringh C.L., Phase separation between nucleoid and cytoplasm in Escherichia coli as defined by immersive refractometry, J. Bacteriol., 1984, 160 (3), 1151.

[14] Robertson B.R., ButTon D.K., Koch A.L., Determination of the biomasses of small bacteria at low concentrations in a mixture of species with forward light scatter measurements by flow cytometry, Appl. Environ. Microbiol., 1998, 64 (10), 3900.

[15] JONASZ M., FouRniER G., STRAMSKi D., Photometric immersion refractometry: a method for determining the refractive index of marine microbial particles from beam attenuation, Appl. Opt., 1997, 36 (18), 4214.

[16] Morel A., AHN Y.H., Optical efficiency factors of free-living marine bacteria: influence of bacterioplankton upon the optical properties and particulate organic carbon in oceanic waters, J. Mar. Res., 1990, 48 (1), 145.

[17] Twardowski M.S., Boss E., MacDonald J.B., Pegau W.S., Bernard A.H., Zaneveld J.R.V., A model for estimating bulk refractive index from the optical backscattering ratio and the implications for understanding particle composition in case I and case II waters, J. Geophys. Res., 2001, 106 (C7), 14129.

[18] Stramski D., Bricaud A., Morel A., Modeling the inherent optical properties of the ocean based on the detailed composition of the planktonic community, Appl. Opt., 2001, 40 (18), 2929.

[19] ANDREWs S., NOVER D., SCHLADOw G., Using laser diffraction data to obtain accurate particle size distributions: the role of particle composition, Limnol. Oceanogr.: Methods, 2010, 8 (10), 507.

[20] WILEN B.M., JIN B., LANT P., Impacts of structural characteristics on activated sludge floc stability, Water Res., 2003, 37, 3632.

[21] Govoreanu R., Saveyn H., Van Der Meeren P., Nopens I., Vanrolleghem P.A., Direct quantification techniques for activated sludge floc size distribution, Water Sci. Technol., 2009, 60 (7), 1857.

[22] YaO K.M., Habibian M.T., O’Melia C.R., Water and wastewater filtration. Concepts and applications, Environ. Sci. Technol., 1971, 5 (11), 1105.

[23] ZiELINA M., HEJDUK L., Measurement of the depth filters for water treatment, Filtration, 2007, 7 (3), 225. 